\title{
Part of the solution or part of the problem? Reflections on teaching participatory asset mapping
}

\author{
Jonathan Parker*and Sara Ashencaen Crabtree
}

\begin{abstract}
Community asset mapping is widely employed in a diverse range of community development programmes, including work with indigenous groups. Here we discuss the outcome of a participatory asset mapping training programme we were asked to deliver for social and community work students and academics at a university in Peninsular Malaysia. The attendees were planning imminent intervention work with the indigenous Orang Asli communities of Tasik Chini, Pahang, Malaysia, with whom we were undertaking our own separate research at the time. The underpinning philosophy and approach of participatory asset mapping is discussed in terms of its use in the community context. A self-reflexive analysis of research relationships and trainer responsibilities is explored in this discursive, conceptual article.
\end{abstract}

\section{Context and introduction}

Environmental damage and socio-political drives towards modernization and integration into mainstream society, the latter a central social policy for all ethnic groups in Malaysia (Nicholas, 2000; Nicholas, Tuah and Tiah, 2002), have exacted a significant toll on the lifestyles and well-being of the Orang Asli (the indigenous peoples of West Malaysia). Our research and the asset mapping exercise discussed here focused on the Orang Asli communities living around Tasik (Lake) Chini in Pahang, Malaysia.

\footnotetext{
*Address for correspondence: Jonathan Parker, Social Sciences \& Social Work, Bournemouth University, Bournemouth, Dorset, UK; email: parkerj@bournemouth.ac.uk
} 